\title{
Logoterapia e o sentido do sofrimento: convergências nas dimensões espiritual e religiosa
}

\author{
Neir Moreira1 - Universidade Federal do Paraná, Curitiba, Brasil \\ Adriano Holanda - Universidade Federal do Paraná, Curitiba, Brasil
}

\begin{abstract}
Resumo
O presente artigo tem o objetivo de analisar o sentido do sofrimento em Logoterapia - psicoterapia do sentido que propõe a compreensão da existência através dos fenômenos tipicamente humanos, especificamente das convergências nas dimensões espiritual e religiosa. Com base no resgate do conceito de vontade de sentido, pretende-se estabelecer tanto uma relação entre os conceitos de pathos, finitude e morte quanto sua articulação com a perspectiva do Homo patiens em Logoterapia; assinalando o lugar da culpa, da doença, da dignidade, da responsabilidade e do sentido nesse contexto. Ademais, considerando a natureza do sofrimento como inerente à constituição humana, a teoria de Viktor Frankl considera a resiliência uma adaptação positiva do homem em resposta às adversidades, as quais possibilitam ao homem superar-se. $\mathrm{O}$ texto também pontua as dimensões essencialmente humanas, enfatizando a dinâmica do Homo religiosus e a dimensão noética como fatores fundamentais no processo de identificação, enfrentamento e superação do sofrimento.

Palavras-chave: Logoterapia, Viktor Frankl, Sofrimento, Resiliência, Sentido.
\end{abstract}

\section{Logotherapy and the meaning of suffering: convergences in the spiritual and religious dimensions}

\begin{abstract}
This present article has the purpose of analyzing the meaning of suffering in Logotherapy - psychotherapy of meaning that seeks to comprehend existence by typical human phenomenon, specifically through the convergences in the spiritual and religious dimensions. From the rescue of the meaning's will concept, it intends to establish a relation both in the concept of pathos, finitude and death, as well as its articulation with Homo patiens perspective in Logotherapy; distinguishing the place of guilt, disease, dignity, responsibility and meaning in this context. Furthermore, considering the nature of suffering as inherent to the human constitution, the theory of Viktor Frankl considers resilience a positive adaptation of man in response to adversities, which enables him to overcome them. The text also indicates the essentially human dimensions, emphasizing the Homo religiosus dynamics and the noetic dimension as fundamental factors in the process of identifying, confronting and overcoming suffering.

Keywords: Logotherapy, Viktor Frankl, Suffering, Resilience, Meaning.
\end{abstract}

A Logoterapia é uma escola psicológica de caráter multifacetado - de cunho fenomenológico, existencial, humanista e teísta -, conhecida também como a "Psicoterapia do Sentido da Vida" ou, ainda, a Terceira Escola Vienense de Psicoterapia. A teoria de Viktor Emil Frankl (1905-1997) concebe uma visão de homem distinta das demais concepções psicológicas de seu tempo ao propor a compreensão da existência mediante fenômenos especificamente humanos e a identificação de sua dimensão noética ou espiritual, a qual pela sua dinâmica própria pode despertar a vivência da religiosidade.

Se Copérnico ousou retirar a Terra do centro das órbitas planetárias e Kant ousou retirar o objeto do conhecimento do centro mesmo da epistemologia, pode-se afirmar que Frankl livrou a psicoterapia do introspectivismo, desconstruindo a noção de uma autorrealização solipsista do centro das motivações primárias do ser humano (Pereira, 2007). A questão não deveria ser "o que eu ainda devo esperar da vida",

${ }^{1}$ Endereço para correspondência

Rua Senador Xavier da Silva, 467, Centro Cívico - 80530-000 Curitiba-PR

E-mail: neirmoreira@hotmail.com porém, “o que a vida espera de mim". Kierkegaard utiliza a seguinte metáfora para relacionar o esforço humano na busca da felicidade: a porta da felicidade abre-se "para fora", ou seja, ela fecha-se exatamente para quem tenta empurrá-la para dentro; já Frankl, a partir de sua experiência nos campos de concentração, foi mais longe, apontando para uma dimensão que só Deus pode mensurar, na fidelidade ao sentido da existência, à missão do ser humano sobre a face da terra. "Não se trata da busca de um, mas da busca do sentido" (Gomes, 1988, p. 31).

Para a logoterapia "o método fenomenológico é o que deve ser tomado, pois o fenômeno não é a aparência, e sim, a manifestação ou revelação de que há a coisa mesma ou o ser em si, sendo o abrir-se e o manifestar-se da própria realidade vivida pelo sujeito" (Pettengill \& Angelo, 2000, p. 92).

A logoterapia se caracteriza pela exploração da experiência imediata com base na motivação humana para a liberdade e para o encontro do sentido de vida. Ela inaugura também um novo campo, o qual Frankl define como uma psicoterapia orientada para o espírito. A rigor, para Frankl, a logoterapia origina-se "do" espiritual, enquanto a análise existencial se dirige "para" o espiritual. A análise existencial focaliza a luta do homem pelo sentido - não apenas o do sofrimento, 
mas também o sentido da vida (Frankl, 1978). A logoteoria, por sua vez, é a fundamentação teórica da logoterapia com a finalidade de proporcionar o saber necessário para uma leitura de mundo a partir dos seus conceitos fundamentais.

\section{A vontade de sentido}

Viktor Frankl reconheceu - especialmente na psicanálise freudiana e na psicologia individual adleriana, o mesmo problema -

a preocupação com um equilibrio interno, numa perene busca pela cessação de tensão, como objetivo maior da gratificação dos instintos e da satisfação das necessidades, constituindo-se, assim, o fim de toda atividade que envolva a vida. (Pereira, 2007, p. 127)

O que de fato impulsiona o homem não é nem a vontade de poder (como aponta Adler), nem a vontade de prazer (como em Freud), mas sim o que Frankl chama de vontade de sentido.

Para Frankl (1991), o homem só se torna homem e só é completamente ele mesmo quando fica absorvido pela dedicação a uma tarefa, quando se esquece de si mesmo a serviço de uma causa, ou no amor a uma pessoa. É como o olho, que só pode cumprir sua função de ver o mundo enquanto não vê a si próprio. O sentido tem um caráter objetivo de exigência e está no mundo, não no sujeito que o experiencia.

$\mathrm{Na}$ logoterapia, a vontade de sentido é orientada para uma realização de sentido, a qual provê uma razão para a felicidade; isto é, "com uma razão para ser feliz, a felicidade surge automaticamente como efeito colateral" (Pereira, 2007, p. 129). Nesse contexto, as noções de "felicidade", de "prazer" ou de "poder", como objetos da busca última do homem, são negadas. E essa busca patológica de uma felicidade incondicional foi denominada por Frankl como "princípio autoanulativo", segundo o qual quanto mais o homem persegue uma ideia acabada de felicidade, prazer ou sucesso, em detrimento da realização de sentido, mais ele se distanciará desse objetivo. Para Frankl, não se deve buscar a felicidade, pois à medida que houver uma razão para ela, então ela decorrerá espontânea e automaticamente. Ele inclusive utiliza a metáfora do bumerangue, o qual apenas volta ao lançador se o seu alvo não tiver sido atingido. Assim, a "auto-realização, se transformada num fim em si mesmo, contradiz o caráter auto-transcendente da existência humana" (Pereira, 2007 citado por Frankl, 1988, p. 38).

Ao falar de sentido, estamos fazendo referência ao significado, à coerência, à busca de propósito e finalidade. Frankl nos expressa como o homem que perdeu o sentido cai em um vazio existencial e sofre; esta frustração existencial pode desembocar em uma sintomatologia neurótica que, como já mencionamos, o dito autor denomina noogênica (Perez, 1997, p. 65).

Ao utilizar o termo noodinâmica, Frankl critica as concepções de saúde mental a partir do ideal do equilíbrio homeostático, pois segundo ele, uma determinada tensão é necessária para a existência humana. A noodinâmica é a tensão essencialmente humana, é a própria dinâmica existencial; é a tensão que se estabelece entre o homem e o sentido, entre o ser e o dever-ser. E nela está presente a liberdade a qual permite escolher uma ou outra possibilidade (Roehe, 2005).

O de que o ser humano realmente precisa não é um estado livre de tensões, mas antes a busca e a luta por um objetivo que valha a pena, uma tarefa escolhida livremente. O ser humano precisa não de homeostase, mas daquilo que chamo de "noodinâmica". Há muita sabedoria nas palavras de Nietzsche: "Quem tem um por que viver pode suportar quase qualquer como" (Frankl, 1985, p. 95-96).

A logoterapia objetiva a conscientização do espiritual. Em sua especificação como análise existencial, ela esforça-se especialmente em levar o homem à consciência do seu ser-responsável, enquanto fundamento vital da existência humana (Frankl, 2003). Essa responsabilidade, todavia, significa sempre responsabilidade perante um sentido.

Niilismo é negação de sentido. "Todo o niilismo se caracteriza pelo ceticismo em relação ao sentido, ceticismo esse, acompanhado de um relativismo quanto aos valores" (Frankl, 1978, p. 261). O relativo, em vez de constituir uma refutação do absoluto, na verdade, necessita dele. Afinal, as coisas relativas apenas provam, documentam e testemunham a existência do absoluto que as condicionou. Tanto o valor quanto o sentido são aplicados às coisas na medida em que o são assumidos em nome de algo mais elevado, por amor a alguém, num sacrifício. E é exatamente aqui que consiste a verdadeira relatividade dos valores. Curiosamente, por mais paradoxal que possa parecer, as coisas têm valor para serem sacrificadas. "O que sacrifica dá ao sacrifício sentido, valor, preço. Dar sentido quer dizer entregar-se. Não é o que eu guardo comigo que retém valor; é o que eu sacrifico que adquire valor" (Frankl, 1978, p. 263).

Padecer de vida sem sentido é um sofrimento, mas não uma doença. Porém, é a vida realmente destituída de sentido? E se o tivesse, seria possível comunicá-lo? A sociedade contemporânea satisfaz praticamente a maioria das necessidades do homem e algumas delas são criadas principalmente pelo consumismo. Todavia, só uma necessidade nada 
recebe, e ela é a necessidade de sentido do homem, ou seja, sua vontade de sentido. Um exemplo apontado por Frankl: o que deprime as pessoas não é o desemprego em si (comum na sociedade atual), mas a sensação de falta de sentido decorrente disto. O peso maior não é ônus financeiro, e sim as pressões psíquicas sofridas pelos desempregados (Frankl, 1990). Ademais, em qualquer situação humana o indivíduo pode encontrar o sentido; mesmo no último momento da vida há possibilidades de tê-lo. Até diante daquilo que Frankl (1993) chamou de "tríade trágica" - a dor, a culpa e a morte - é possível encontrá-lo.

O sentido não é moldado pela mente, mas a mente pelo sentido. Em vez de criar um sentido, a mente tem de submeter-se a ele, uma vez encontrado. Segundo Frankl, o sentido da vida é uma realidade ontológica e não uma criação cultural. $\mathrm{O}$ sentido da vida simplesmente existe: trata-se apenas de encontrálo. Universal no seu valor e individual no seu conteúdo, o sentido da vida é encontrado mediante uma investigação do paciente e do terapeuta em busca de resposta à questão sobre o que somente o paciente, $\mathrm{e}$ absolutamente mais ninguém, pode fazer. Para Frankl, nenhum homem inventa o sentido da vida: cada um é cercado e impelido pelo sentido da própria vida. O sentido não pode ser dado ou criado, mas deve ser encontrado. E mais, o sentido não só deve ser achado, como ele pode ser achado. "E nessa busca o homem é orientado pela consciência. Em uma palavra, a consciência é o órgão do sentido, é a capacidade de descobrir o sentido único e irreprodutível que se esconde em cada situação" (Frankl, 1978, p. 19).

A vida, diz Frankl (1978), permanecerá dotada de sentido, mesmo se todas as tradições desaparecerem e mesmo se nenhum valor de aplicação geral se mantiver. Conclusivamente, o que o homem procura não é a felicidade em si, mas uma razão para ser feliz. É a vontade de sentido na práxis da existência humana.

\section{Pathos e logoterapia}

$\mathrm{Na}$ história da humanidade, o sofrimento sempre se fez presente, decorrente de vários fatores: guerras, pobreza, pandemias, violência (no seu mais completo termo), desnutrição, etc. Hodiernamente, os dados apenas têm aumentado geometricamente, se considerarmos as estatísticas. Obviamente, na atuação psicológica, "a questão do sofrimento humano tem chamado muito a atenção. $O$ sofrimento está muito presente. E a conjuntura social contribui para isso de uma forma que não ocorria nas sociedades tradicionais" (Silveira, 2007, p. 16).

O sofrimento é inerente ao ser humano. Inclusive ele traz sentido à vida em diferentes graus de intensidade ao longo da existência. E o desafio se constitui em decidir o que fazer diante dele. Viktor Frankl, nos campos de concentração, "experimentou e concluiu que a liberdade máxima do ser humano está em escolher a atitude diante das situações limite da vida e da morte. Existe sempre algo ou alguém que mereça a luta pela sobrevivência" (Sulzbach, 2008, p. 13). A decisão consiste em "entregar-se" passivamente ou "assumir ativamente" a luta por algo ou alguém dignos dessa dor e sofrimento.

Outro conceito importante na logoterapia é a concepção de Homo patiens, que designa como o homem cumpre com sua orientação ontológica para a realização de sentido, não obstante o sofrimento e apesar do fracasso, considerando-se serem dois critérios não excludentes de análise. $\mathrm{O}$ desmembramento de ambos os eixos permite o entendimento de por que é possível a satisfação apesar do fracasso, bem como o desespero apesar do êxito. A busca desse sentido de caráter objetivo funda-se no mundo, não no sujeito, e constitui o fim último de toda a atividade que envolve a existência humana (Pereira, 2007).

Analisando o problema do sentido da vida é possível distinguir, mesmo que de modo bastante geral, três categorias de valores: valores criadores, valores vivenciais e valores de atitude. Enquanto na primeira categoria o homem se realiza mediante um fazer, na segunda, ele se realiza através de uma passiva acolhida (pela arte, por exemplo); já na terceira categoria, ele somente se realiza quando algo se tem que aceitar precisamente tal qual é. E isso significa que a vida humana pode atingir a sua plenitude, não apenas no criar e gozar, senão também no sofrimento (Frankl, 2003).

\section{Pathos e sentido}

A análise existencial tem demonstrado que o sofrimento tem um sentido, e que além do sofrimento, a necessidade, o destino e a morte fazem parte da vida. "Nenhum desses elementos se pode separar da vida sem se lhe destruir o destino. Privar a vida da necessidade e da morte, do destino e do sofrimento, seria como tirar-lhe a configuração, a forma" (Frankl, 2003 , p. 154). A vida só adquire forma e figura com as marteladas que o destino lhe dá quando o sofrimento a põe ao rubro.

Só quando o homem já não tem nenhuma possibilidade de realizar valores criadores; só quando ele já não está realmente em condições de configurar o destino - só então pode realizar os valores de atitude; só nessa altura tem algum sentido "carregar a sua cruz". A essência de um valor de atitude reside precisamente no modo como um homem se submete ao irremediável; quer dizer: o pressuposto da 
verdadeira realização dos valores de atitude consiste em se tratar realmente de qualquer coisa de irremediável (Frankl, 2003, p. 155).

O sentido do sofrimento nem sempre é evidente, e quando evidenciado, é apenas num tempo tardio e, portanto, é restritivo. Os exemplos geralmente são extraídos da própria experiência, "donde se depreende que algum fato realmente doloroso em sua vida bem pode ter tido, a partir de uma visão mais tardia, um sentido que naquela ocasião não lhes era patente" (Lukas, 1989, p. 198).

Não pode, porém, ser suficientemente ressaltado que o sofrimento não é de forma alguma necessário para se preencher um sentido, ainda que possa valer muito bem, que o preenchimento de um sentido é possível apesar de um sofrimento, conquanto o sofrimento seja inevitável (Frankl, 1990, p. 51).

Ademais, a liberdade espiritual do homem the concede a oportunidade até o último instante de tornar sua vida plena de sentido; afinal, se a vida tem um sentido, então também o sofrimento tem um.

\section{Pathos e culpa}

Para a logoterapia, há nas emoções humanas uma profunda sabedoria, para além da racionalidade. Com efeito, chorar o que se perdeu parece ao senso comum algo tão inútil e destituído de sentido como o próprio arrepender-se de uma culpa. Entretanto, tanto o luto quanto o arrependimento têm o seu sentido na história interior do homem. Frankl (2003) afirma que o arrependimento tem o sentido e a força de fazer com que um fato externo se converta em algo nãoacontecido, enquanto a tristeza do luto tem o sentido e a força de fazer com que aquilo que existiu de algum modo continue a existir.

E o arrependimento, conforme Scheler salientou, pode apagar uma culpa: não, evidentemente, no sentido de que ela deixe de ser imputada ao respectivo sujeito; mas sim no sentido em que este, por assim dizer, se soergue, ao renascer moralmente. Tal possibilidade de converter o já acontecido em algo de fecundo para a história interior do homem nem de longe está em contradição com a sua responsabilidade, mas antes numa relação dialética. Com efeito, o tornarse culpável pressupõe responsabilidade (Frankl, 2003, p. 152).

Para a psicologia clássica, que preconiza a culpa como secundária, a busca de poder e prazer conduz, inconscientemente, a uma procura do sofrimento e da penitência para o alívio. Tanto a psicanálise quanto as demais teorias imanentistas asseguram a autodestruição irremediável sem quaisquer possibilidades de interferência, uma vez que o circuito seria retroalimentado pelas tendências inconscientes.
Em contrapartida, quando o homem busca intencionalmente um sentido, apesar da ameaça de destruição, o sofrimento passa a ser um enfrentamento intencional desses condicionamentos e não uma situação penitente inconsciente. Assim sendo, o sofrimento tem um sentido inerente quando ele brota da culpa existencial ou real.

Para Rodrigues (1991), a culpa é considerada a "síndrome inescapável", uma vez que o momento do erro já está no passado e não pode ser restaurado. Ou seja, na culpa, ou "adversidade inescapável", o homem se depara com as consequências inevitáveis dos seus equívocos. A premissa existencialista assegura ao indivíduo que a adversidade tem um real sentido, isto é, visa

motivá-lo a mudar e crescer, desafiando a sua dimensão espiritual na sua capacidade mais profunda de autotranscendência. Crescimento este que só pode se realizar se o paciente aceitar sua culpa, aceitar as adversidades e as consequências de seus atos errôneos. (Rodrigues, 1991, p. 167)

A rigor, quais os fatores determinantes na intervenção logoterapêutica? A medicação farmacológica específica, as técnicas psicoterapêuticas, ou o apoio e a empatia? $\mathrm{Na}$ verdade, a conjugação de todos esses fatores contribui intensamente, mas é a dimensão noética que envolve a decisão de valores, na dimensão do logos, que oferece os máximos recursos.

\section{Pathos, doença e dignidade}

É necessário fazer uma distinção fundamental entre as doenças (incluindo as mentais) e o sofrimento. Se o homem pode estar doente sem "sofrer" no sentido verdadeiro e próprio do termo, ele também sofre para além de todo o ser-doente, ou seja, trata-se do padecimento puramente humano que se insere na essência e sentido da própria vida humana. Com isso, Frankl (2003) afirma que há situações em que o homem se pode realizar plenamente a si mesmo no puro sofrimento e apenas no puro sofrimento. Agora é possível compreender por que razão Dostoievski afirmou que só uma coisa tinha que temer: o não ser digno das suas penas.

Segundo Viktor Frankl, sofrimento e doença não se equivalem. $O$ homem pode sofrer sem estar doente, e estar doente sem sofrer. O sofrimento é tão inerente ao humano - como já definiu Jaspers - que eventualmente o não-sofrer pode ser uma doença. E há estados psíquicos doentios nos quais o homem, exatamente por não sofrer, sofre (Frankl, 1990).

Viktor Von Weizsäcker já afirmara que o doente enquanto sofredor está de alguma forma acima do médico que o atende. 
Um médico que tenha a suficiente finura de sensibilidade para os imponderáveis de uma situação sempre terá, diante de um doente incurável ou de um moribundo, a sensação de não se poder aproximar dele sem uma certa vergonha. É que, realmente, quando assim sucede, o médico fica impotente e incapaz de arrancar a vítima à morte; aliás, enquanto o paciente surge como um homem que enfrenta com firmeza o seu destino e, ao assumi-lo num sereno sofrimento, leva a cabo, no plano metafísico, uma autêntica realização, o médico, no mundo físico, na esfera das realizações médicas, não faz mais do que falhar (Frankl, 2003, p. 158).

Assim como o destino, o sofrimento também faz parte da nossa vida, ou seja, se a vida tem um sentido, o sofrimento também o tem. O padecimento, enquanto necessário, é uma possibilidade de algo pleno de sentido. Sofrimento desnecessário é sofrimento destituído de sentido, todavia, sofrimento necessário significa sofrimento permeado de sentido.

Não é apenas o somático que se abre ao psíquico, mas igualmente o psíquico ao espiritual. Enquanto o corpóreo precisa do psíquico para a sua realização, da mesma forma depende do espiritual para a sua plena realização. "Se alguma coisa corporal é 'possível', é 'realizada' pelo psíquico, porque é uma 'necessidade' espiritual' (Frankl, 1978, p. 122).

Segundo a logoterapia, a dignidade do homem permanece intacta mesmo depois da perda da utilidade em razão da desorganização psicofísica da pessoa espiritual. Da mesma forma que a pessoa espiritual está "atrás" do fato mórbido psicofísico, igualmente a sua dignidade está "acima" da perda do valor biossocial. Frankl acrescenta que enquanto não estivermos profundamente convencidos da invulnerabilidade dessa dignidade será apenas uma questão de maior ou menor foco quanto à possibilidade de flertarmos com a eutanásia, por exemplo. Para ele, “a pessoa espiritual deixa-se perturbar, mas não destruir por uma enfermidade psicofísica" (Frankl, 1978, p. 120). O homem é factualmente condicionado, mas facultativamente incondicionado.

\section{Pathos e responsabilidade}

A "tríade trágica" - sofrimento, culpa e morte - em Frankl, é a manifestação da característica antropológica da análise existencial em logoterapia, ou seja, o ser-humano-é-finito.

A resposta sobre o sentido do trágico é encontrada na atitude mesma que elegemos ante uma situação que se nos apresenta tragicamente. Só o ser humano tem o privilégio de eleger uma atitude frente ao sofrimento que se apresenta como tal. (Xausa, 2003, p. 84)
Apenas diante daquilo que é decisão puramente sua é que a pessoa é responsável. “O ser humano propriamente dito começa onde deixa de ser impelido, e cessa quando deixa de ser responsável" (Frankl, 1993, p. 19). Assim sou, em última análise, responsável por tudo (Frankl, 1978, p. 175). A responsabilidade significa aquilo por que somos "atraídos" e a que "nos subtraímos". Um mergulho na essência da responsabilidade humana nos permitirá um estremecimento pela dualidade: temível-sublime.

Temivel é saber que a cada momento arco com a responsabilidade pelo momento seguinte; que todas as decisões, as de menor e as de maior monta, são decisões "para toda a eternidade"; que em cada momento realizo ou desperdiço uma possibilidade, a possibilidade deste momento preciso e único. Cada momento encerra milhares de possibilidades, mas eu só posso escolher uma delas para realizá-la, condenando todas as outras simultaneamente ao não-ser, e isto também "para toda a eternidade"! Não obstante, é sublime o saber que o futuro, tanto o meu próprio como o das coisas e o dos homens que me rodeiam, em certa medida, por pequena que seja, depende da decisão que eu tomo em cada instante. O que eu realizar com essa decisão, o que com ela "criar no mundo", é qualquer coisa que ponho a salvo na realidade, preservando-o da caducidade (Frankl, 2003, p. 66-67).

De acordo com Frankl (1978), a humanidade atingiu um ponto máximo de ciência, de consciência e de saber. Além disso, a um máximo de responsabilidade, mas ao mesmo tempo, a um mínimo da consciência da responsabilidade. E o objetivo primordial da intervenção logoterapêutica não é outro senão o apelo à consciência da responsabilidade.

Se quisermos levar nossos pacientes à consciência de sua responsabilidade, teremos que tornar presente o caráter histórico da existência e, com isso, a responsabilidade do homem para com a vida. Ao paciente sentado diante de nós na hora da consulta recomendamos que aja como se estivesse, no final da vida, folheando sua biografia e se detendo exatamente no capítulo referente ao momento atual e que, por milagre, lhe fosse permitido decidir o conteúdo do capítulo seguinte e corrigir o que lhe parecesse passível de alteração (Frankl, 1978, p. 229).

Admite-se que o sofrimento purifica o homem. Afinal, "a resposta que o homem sofredor dá, por meio do 'como', ao 'porquê' do sofrimento é sempre uma resposta sem palavras, mas, reiteremos, ela é, do prisma da fé num super-sentido, a única significativa" (Frankl, 1978, p. 283). Ademais, tão significativo quanto o próprio sofrimento é o seu caráter cooperativo, compassivo. 


\section{Sentido e Resiliência}

Resiliência é entendida como a capacidade do homem enfrentar as situações, sobrepor-se e sair fortalecido pelas experiências adversas. A resiliência pode ser definida como uma adaptação positiva em resposta a determinada adversidade; superando-a, inclusive. Significa não apenas suportar uma situação adversa, mas comprometer-se em uma nova dinâmica de vida. Em logoterapia, o conceito de resiliência é usado como fator protetor do psiquismo e de transformação dos comportamentos negativos em novas possibilidades. A resiliência faz a pessoa encontrar motivos que favoreçam a descoberta de valores além, por trás da dor e do psicológico (Sulzbach, 2008, p. 14).

Silveira (2007) distinguiu três componentes essenciais ao conceito de resiliência, a saber: 1) a noção de adversidade, trauma, risco ou ameaça ao desenvolvimento humano; 2) a adaptação positiva ou superação da adversidade; e 3) o processo que considera a dinâmica entre os mecanismos emocionais, cognitivos e socioculturais que influenciam $\mathrm{O}$ desenvolvimento humano. Para ele, o conceito de resiliência é bem formulado, porém insuficiente para clarificar o que subjaz e motiva a resiliência. Nesse vácuo, a logoterapia, de Viktor Frankl, pode jorrar luz; ou seja, "através da atitude da pessoa de buscar sentido para a vida, pode-se desenvolver resiliência - a resistência diante da adversidade" (Silveira, 2007, p. 81). É a partir do sentido que a pessoa golpeada pela vida motiva-se para reconstruir-se, mantendo a esperança, em busca dos recursos que fomentem a resiliência. As pesquisas realizadas sobre a resiliência têm evidenciado a importância da relação entre o resiliente e o outro, a alteridade no contexto da resiliência (Silveira \& Mahfoud, 2008).

É possível, a partir do sofrimento, o homem superar tanto a si mesmo quanto em relação ao próprio contexto e existência? A resposta é positiva, desde que seja deslocado o foco da dor para além dela, ou seja, para as possibilidades de superação. Ao invés de se concentrar nas enfermidades, necessidades e deficiências do indivíduo, é preferível um modelo de prevenção e promoção de saúde com foco nas potencialidades tanto da pessoa quanto do meio em que vive (Silveira, 2007; Silveira \& Mahfoud, 2008). Ou seja, a resiliência não é de responsabilidade apenas do indivíduo, mas de toda a ecologia na qual está inserido, quer seja família, quer seja amigos, profissionais e todos envolvidos na promoção da resiliência.

Ademais

em todas as pesquisas feitas sobre resiliencia sempre se encontrou a importância de existir a relação entre a pessoa resiliente e um outro - um amigo, um parente, um conhecido, enfim, alguém com quem se possa compartilhar vivências e em quem se possa confiar. (Silveira \& Mahfoud, 2008, p. 573)

Fica claro que doença não significa perda de sentido, nem tampouco traz obrigatoriamente $\mathrm{O}$ empobrecimento do sentido da existência consigo. Ao contrário, desde que possível, ela é sempre algo pleno de sentido. Pode inclusive significar um ganho existencial. Recuperando o conceito de autotranscendência em Viktor Frankl, é possível articular a relação com a resiliência, pois o homem sempre pode avançar para além das suas dificuldades, quando encontra um sentido para ir adiante, obviamente.

Para a logoterapia nenhum sofrimento humano é comparável. O padecimento humano é único, singular e original, assim como o é cada indivíduo. "Falar das diferenças de grandeza do sofrimento seria por princípio sem sentido; uma diferença, porém, que realmente importa, é a diferença entre sofrimento com e sem sentido" (Frankl, 1990, p. 105).

Considerando a transitoriedade do tempo, é vital vivenciar a melhor atitude, sem perder a chance de concretizá-la. Desenvolver a resiliência é algo construído a cada momento, a cada escolha. Dessa forma, "o sentido e realização no passado, relembrados, constituem-se em força para viver melhor o presente e suportar as adversidades" (Silveira, 2007, p. 91). A rigor, a logoterapia é a expressão fiel de uma filosofia encarnada, cujo nome assume Viktor Frankl. Ele, sim, foi um modelo de resiliência.

Silveira (2007) alista os diversos pilares para o desenvolvimento pleno da resiliência: adaptação às situações adversas; a autoestima como consequência da busca do sentido; a esperança e a fé, as quais são importantes na dinâmica da resiliência; diante da adversidade, a religião e a espiritualidade podem agir como um consolo além da nossa compreensão; "a busca de sentido envolve uma perspectiva de futuro" (Silveira, 2007, p. 100); a liberdade do homem o permite se posicionar diante do sofrimento; o senso de humor é fundamental para lidar com a adversidade; assumir uma atitude positiva diante das dificuldades é o que significa resignação ativa; o cuidado com a saúde é um fator importante; a capacidade de controlar impulsos fortes; a flexibilidade; a capacidade de pedir auxílio; a criatividade na dimensão noológica (espiritual); o reconhecimento do valor mútuo no encontro existencial; e a empatia, que pode ser entendida como a possibilidade do sujeito tornar-se capaz de se colocar no lugar do outro, sentir o que o outro sente e compreendê-lo (Frankl, 1990).

Via de regra, o homem se movimenta em um nível horizontal, entre os pólos sucesso e insucesso, e 
esta é a dimensão do homo sapiens. Todavia, a dimensão do homo patiens está no nível vertical. Este, por sua vez, é o homem que sofre, que resiste, resiliente ao sofrimento, o qual preenche o sentido e realiza-se. Nesse contexto, os pólos são satisfação e desespero. E, em virtude da distinção dimensional, é possível haver satisfação apesar do insucesso, além de desespero, não obstante o sucesso.

$\mathrm{O}$ indivíduo que se eleva acima de si mesmo caminha para a maturidade. As situações extremas conduzem o homem a alcançar tanto a liberdade interior quanto a maturidade. "Sofrer, então, não significa apenas esforçar-se, crescer e amadurecer, mas igualmente enriquecer-se" (Frankl, 1978, p. 241). Ademais, a existência humana se nos oferece a sua maior profundidade, a paixão. A rigor, a essência do homem é ser um sofredor - Homo patiens, o homem que cumpre sua orientação ontológica na busca do sentido, a despeito do sofrimento e apesar do fracasso. A propósito, ao Homo sapiens, contrapõe-se o Homo patiens. "O sacrifício é capaz de dotar de sentido até a morte, enquanto o instinto de conservação, por exemplo, não consegue sequer dar um sentido à vida" (Frankl, 1978, p. 245).

No processo de aprendizado da e na adversidade, surge a necessidade da resiliência, que se torna a operacionalização para o encontro com o sentido da vida. "O sentido da resiliência, então, é a busca de sentido da vida que se traduz em criatividade, aprendizado, superação, crescimento" (Silveira, 2007, p. 105).

\section{Finitude e morte}

A morte é, sem dúvida, a maior adversidade com que o homem se defronta. Não tanto a morte em si, mas o simples conhecimento de que sua vida se extinguirá irreversivel e inescapavelmente. (Rodrigues, 1991, p. 181)

Obviamente, ao tomar conhecimento da morte, as pessoas têm diante de si uma situação de dor e sofrimento; notadamente quando esta morte não se enquadra no padrão e tempo considerados normais. É claro que a finitude da vida é ansiogênica e também uma razão de sofrimento, independente do tempo no qual se dê a morte, das situações em que se desenvolve, e das pessoas envolvidas.

O medo da morte nas pessoas normais leva a uma série de reações de defesa muito conhecidas na rotina do dia a dia: a sensação comum de que "o tempo está passando" irreversivelmente e estamos envelhecendo vem quase sempre imbuída de uma dose de ansiedade (Rodrigues, 1991, p. 181).

$\mathrm{Na}$ logoterapia, é no ser-passado que está tudo preservado. Frankl assegura que "o de que nós precisamos é respeito ao passado, não ao futuro; o passado é inevitável, o futuro, o nosso futuro está à frente da nossa decisão e da nossa responsabilidade" (Frankl, 1978, p. 151).

O homem não é apenas um ser essencialmente individual, mas completamente histórico. Para Frankl (1978), na qualidade de ser histórico, o homem jamais "é", mas sempre "vem a ser". E ele somente será um "todo" quando sua vida terminar; somente então seu "mundo" será concluído. Igual a uma linha circular que se fecha sobre si mesma, de igual modo a vida o faz no momento da morte.

Os elementos constitutivos do sentido da vida humana são dois: o "caráter de algo único" e a irrepetibilidade. E ambos os aspectos essenciais da existência humana manifestam-se simultaneamente na finitude do homem. Tal finitude representa algo que de alguma forma concede sentido à existência, e não algo que lho tire. Para Frankl (2003), a morte não pode corroer o sentido que caracteriza a vida. Ao contrário, o que aconteceria se a vida não fosse finita temporalmente, mas ilimitada no tempo? Se fôssemos imortais, poderíamos adiar as nossas ações infinitamente; e nunca teria a menor importância o realizá-las agora, amanhã ou daqui a dez anos. Em contrapartida, tendo em vista a morte como uma fronteira intransponível do futuro e limite das nossas possibilidades, vemo-nos obrigados a aproveitar o tempo de vida que dispomos e a não deixar passar em vão as ocasiões consideradas irrepetíveis, cuja soma "finita" significa precisamente a vida toda.

A finitude e a temporalidade neste contexto não são apenas um adicional à vida humana, são necessariamente constitutivos do seu sentido. O sentido da existência humana funda-se essencialmente no seu caráter irreversível. A propósito, a máxima da análise da existência poderia ser assim compreendida: Vive como se vivesse pela segunda vez e como se da primeira vez tivesses feito tão falsamente como agora está quase a fažer. É possível também imaginarmos a vida como um filme que estamos "filmando", sem, contudo receber "cortes", ou seja, um filme no qual já não se pode retroceder para desfazer o que foi "tomado". A propósito, "quando se vai ao cinema, é claro que o que mais importa é que o filme tenha um fim, seja ele qual for, pouco importando que seja um happy-end' (Frankl, 2003, p. 111).

O fato de que somos mortais, que nossa vida é finita, que nosso tempo é limitado e nossas possibilidades limitadas, esse fato é que principalmente faz com que pareça pleno de sentido empreender algo, aproveitar uma oportunidade, realizar, satisfazer, aproveitar e preencher o tempo. A morte significa a pressão para tal. Assim, a morte constitui o fundo 
sobre o qual o nosso ser é exatamente um ser responsável (Frankl, 1990, p. 75).

Assim sendo, torna-se essencialmente insignificante a duração da vida humana. Uma vida longa não a torna necessariamente plena de sentido, da mesma forma que a sua eventual brevidade não a destitui de sentido. Não se julga a biografia de uma pessoa, segundo Frankl, pelo número de páginas da obra que o apresenta, mas pelo seu conteúdo.

Não é necessário, portanto, separar a morte da vida, seja de que modo for; porque, a rigor, o que sucede é que a morte faz parte dela! Mas também não é possível "dominá-la", como julga fazer o homem que quer "eternizar-se" pela procriação, pois é falsa a tese de que o sentido da vida se radica na descendência (Frankl, 2003, p. 112).

Em suma, a morte pertence à vida tanto quanto o sofrimento, uma vez que nenhum dos dois torna a existência do homem sem sentido, mas antes plena de sentido. A singularidade da vida, a irrepetibilidade do tempo e a irrevocabilidade daquilo que preenchemos nossa existência (e até a sua ausência) traz real significação à nossa existência. Mesmo porque o ser passado, neste sentido, é a forma mais segura de ser. Ao ser que guardamos no "passado", a "transitoriedade" não pode mais causar dano algum (Frankl, 1990). Afinal, aquilo que irradiamos no mundo será exatamente o que permanecerá de nós quando já tivermos partido.

A morte se revelou plena de sentido na medida em que funda a singularidade da nossa existência e com ela nosso ser responsável; da mesma forma evidencia-se agora a nós a imperfeição do homem que, como ser, necessita de sentido, na medida em que - agora visto positivamente como um valor - apresenta-se como algo que constitui a originalidade de nossa essência (Frankl, 1990, p. 78).

A morte é o resultado da finitude e da transitoriedade da existência humana. "O ser humano não é apenas um ser-para-a-morte, mas um ser-ante-amorte, pois ante ela se decide e toma uma atitude" (Xausa, 2003, p. 84).

Diante da ameaça da morte, trata-se de lutar pelo sentido da morte, do morrer, e caminhar para o derradeiro fenômeno da existência humana de cabeça erguida. "Saber morrer sua morte" em logoterapia significa integrar a morte com o pleno sentido no todo da existência; pois até na morte se satisfaz verdadeiramente o sentido da vida. A vida não se transcende a si mesma longitudinalmente - no sentido da sua própria propagação - , mas "em altura", enquanto teleologicamente orientada para um sentido.

\section{Homo Religiosus e Dimensão Noética}

A humanidade e a animalidade são constituídas pelas dimensões biológica, psicológica e social, todavia, o homem difere dos animais por possuir também a dimensão noética. Apesar das três dimensões, a essência da existência do homem reside na dimensão espiritual. Sendo assim, a existência propriamente humana é existência espiritual. A inclusão das demais dimensões inferiores garante a totalidade do homem.

O termo "espiritual", em Frankl, não tem conotação essencialmente religiosa. Ela é a melhor tradução do original alemão geist que se refere ao noológico. Ademais, a dimensão espiritual é compreendida, fundamentalmente, como a dimensão da vivência da liberdade e da responsabilidade. E falar de existência, na sua dimensão espiritual, significa falar, sobretudo, do "ser-responsável" e do "ser humano consciente de sua responsabilidade" (Frankl, 1993). Não se trata aqui da liberdade das condições biológicas, psicológicas e sociais - comum à humanidade - mas da liberdade para uma decisão diante das circunstâncias, quer cotidianas, quer excepcionais. A dimensão espiritual mostra-se, portanto, como uma dimensão não determinada, mas determinante da existência (Coelho Jr. \& Mahfoud, 2001).

Não é possível apreender o eu porque nós próprios o somos, assim como uma mão não se pode agarrar a si mesma. Na logoterapia, só o conhecimento existencial pode ser absoluto. De acordo com Husserl, “o fenômeno (igual à essência) 'vermelho', quando apreendido no modo 'absoluto', poderá ser contemplado de tal maneira que nem Deus poderia observar diferentemente" (Frankl, 1978, p .91). Ou seja, o espírito não está no corpo e também em parte alguma do espaço. A realidade aqui referida não é ôntica, e sim ontológica: o ente espiritual "é", em realidade, "em" outro ente espiritual. Sujeito e objeto são completamente entrelaçados.

Em nenhum momento a logoterapia afirma que o homem é "composto" de corpo, alma e espírito. $\mathrm{Na}$ verdade, ele é tudo isso unitariamente, todavia, o espírito constitui e garante a unidade. Ou seja, o homem "tem" corpo e alma, mas "é" espírito.

$\mathrm{Na}$ medida em que o homem é espirito, existe como pessoa; porém, neste sentido, pode-se também dizer que a sua existência é una, total e nova. Una, porque indivisivel; total, porque inadicionável; e nova, porque a existência é intransmissivel. (Frankl, 1978, p. 129)

Ademais, enquanto o físico é dado hereditariamente, o psíquico é dirigido pela educação, o espiritual - não podendo ser educado - tem de ser realizado. $\mathrm{O}$ espírito não é substância, mas movimento puro. 
Ressalte-se que o corpóreo é condição e não causa do psicoespiritual. Enquanto a doença física limita as possibilidades de desenvolvimento da pessoa espiritual, o tratamento somático as restitui, dando-lhe novas oportunidades.

Já sabemos que a psicose não é uma enfermidade da pessoa espiritual, é verdadeiramente uma somatose. Adoecer, na significação geral de 'ser doente', só se aplica ao organismo psicofísico. (Frankl, 1978, p. 117).

Assim, tanto a doença quanto o tratamento atuam exclusivamente no aparelho, no instrumento. Para Frankl, a pessoa espiritual permanece intacta, mesmo na psicose - o espírito não é afetado pela patologia "do" espírito. É o psicofísico que adoece, e não o espírito.

A logoterapia como referencial orientado para o sentido certamente há de se ocupar necessariamente do fenômeno da fé. Ademais, "a fé não é um pensar diminuído da realidade da coisa pensada, mas um pensar acrescido da existência daquele que pensa" (Frankl, 1978, p. 275). Para Frankl, a fé não deve ser rígida, mas firme. Afinal,

quem não sente firme em sua fé se agarra com ambas as mãos a um dogma inalterável; quem está seguro na sua fé dispõe das mãos livremente e as estende para os seus semelhantes, com os quais está em comunicação existencial. (Frankl, 1978, p. 280)

O anseio mais profundo do homem não é olhar para si mesmo, mas direcionar o seu olhar para o mundo exterior, em busca do sentido. Em função da sua "autocompreensão ontológica pré-reflexiva", ele se autorrealiza exatamente na proporção em que "se esquece de si mesmo" ao dedicar-se a um trabalho ou a uma pessoa. Frankl (1993) diferencia a dimensão espiritual da experiência religiosa, considerando esta última como uma das manifestações da dimensão noética. $\mathrm{Na}$ referida obra, o autor fala sobre a possibilidade da espiritualidade se manifestar no inconsciente. A pessoa profunda, a saber, o espiritualexistencial em sua dimensão profunda é sempre inconsciente.

A propósito, uma das características mais distintas dessa dimensão é a "autotranscendência", isto é, o homem a partir da intencionalidade é dirigido para algo ou para alguém fora de si próprio. E por meio desta autotranscendência o espírito se realiza; ou seja, apenas na execução de atos espirituais. Isso é definido como "realidade de execução", na qual a pessoa fica tão absorvida em seus atos espirituais que não é passível de reflexão na sua essência através de um processo indutivo a partir de três fenômenos especificamente humanos (Coelho Jr. \& Mahfoud, 2001).
"O homem não é apenas um ser que reage e ab-reage, mas também que se auto-transcende" (Frankl, 1990, p. 29). Para Frankl, o caráter de "dever" da consciência moral não procede do homem, mas da transcendência - algo maior que o homem - por se constituir "autoridade" que dirige o querer eficazmente em direção à realização do sentido de vida. Dessa forma, o relacionamento com o transcendente revela-se como uma característica distintamente humana, ontológica.

A relação transcendental pode ser apreendida pelo sujeito por meio da experiência do diálogo, no qual o transcendente é definido como um "Tu". Ao homem que experiencia tal possibilidade, Frankl o denomina de bomo religiosus. Contudo, este relacionamento com o Tu também pode estar oculto, inconsciente ou reprimido, mas o homem está sujeito a ele. A rigor, Frankl investigou o inconsciente noético ${ }^{2}$ a partir da análise de sonhos e constatou a presença de conteúdos religiosos reprimidos, mesmo em pessoas irreligiosas (Coelho Jr. \& Mahfoud, 2001). A partir desses estudos com análises de sonhos foi possível confirmar a existência no inconsciente noético de uma religiosidade no sentido relacional com o tu, de uma relação constante com o transcendente. Frankl a considerou como uma "fé inconsciente".

Para Frankl, falar de um relacionamento inconsciente com Deus ou ainda dessa presença divina como pano de fundo da consciência moral não significa afirmar que o inconsciente seja divino ou que Deus esteja "dentro" do homem e preenchendo o seu inconsciente. Engano igual também seria admitir que o inconsciente seja onisciente, bem como acreditar que esta relação inconsciente provoque um contato do homem com Deus. "A verdadeira religiosidade não tem caráter de impulso, mas antes de decisão" (Frankl, 1993, p. 56).

Apenas Deus pode afirmar de si mesmo "Eu Sou o que Sou"3. E pode fazê-lo porque é actus purus, potência atuada, possibilidade realizada.

Deus é uma congruência de ser e ser-assim, de existentia e essentia. No homem, porém, há sempre uma discrepancia entre, de uma parte, o ser e, de outra, o poder e o dever. Esta discrepância, esta distância entre existência e essência são inerentes à vida bumana como tal. (Frankl, 1978, p. 232)

Assim, encontrar resposta para a busca do sentido absoluto não está ao alcance do homem.

\footnotetext{
2 Referindo-se à teoria freudiana, Frankl (1991) propõe que, tal como os processos instintivo-inconscientes (dimensão psicológica), o homem apresenta fenômenos noético-inconscientes (dimensão noética). Para Frankl, o eu (nous) em sua origem é inconsciente, assim como o olho que, vendo, não pode ver a si mesmo, ou seja, o eu não pode autoobservar-se.

${ }^{3}$ Exxodo 3.14.
} 
Viktor Frankl afirma que o homem é precisamente um ser médio, ou seja, um ser que se situa entre potentia e actus. Deus, por sua vez, é definido como actus purus. Para ele, a humanidade tem sempre uma oportunidade para progredir e se desenvolver. A humanização está, obviamente, inacabada. Recuperando o conceito de Sabath, Frankl destaca que a humanização se revela não como criação, mas como capacitação do homem, e esta aguarda a sua autorrealização (Frankl, 1978).

A logoterapia não concebe da mesma forma o fenômeno da fé como crença em Deus, mas concebe-a como uma crença ampliada no sentido; sendo assim, é legítimo que ela não se ocupe apenas com a "vontade de sentido", mas também com a vontade de um sentido último, um "superssentido". Ou seja, a fé religiosa é uma crença no superssentido". Para Ludwig Wittgenstein, "crer em Deus significa ver que a vida tem um sentido" (Frankl, 1990, p. 58). A rigor, o supersentido não necessita de comprovação; a ausência de sentido da totalidade, sim, é que deveria ser provada.

O super-sentido aparece no "efeito", não na intenção. O super-sentido, porém, impor-se-á independentemente do que en venha a fazer ou deixe de fazer, com minha ajuda ou sem ela, com minha cooperação on sem me levar em consideração. (Frankl, 1978, p. 235)

Em Frankl (2003), a iniciação na dimensão supra-humana, efetivada na fé, funda-se no amor. E mais, quer seja entendido como conceito-limite ou em termos religiosos, a fé no plano do suprassentido tem grande importância psicoterápica e psico-higiênica. Tal fé é criadora. E brotada duma força interior esta fé torna o homem mais forte. Para o crente, não há, em última instância, nada sem sentido.

A alma humana parece comportar-se igual a uma abóbada que, prestes a ruir, é sustentada pelo peso que lhe é imposto. Ou seja, a alma do homem, até certo limite, torna-se mais firme quando experiencia uma determinada "carga". Assim, a libertação repentina da opressão que perdurou um determinado tempo pode colocar em risco a própria estabilidade da alma (Frankl, 1990). À queda espiritual-psíquico-física somente uma psicoterapia que tratasse, sobretudo de dar apoio espiritual e de possibilitar a descoberta do conteúdo e sentido da vida teria condições de um restabelecimento e restauração à existência humana.

$\mathrm{Na}$ experiência religiosa, a consciência moral a VOz da transcendência - guia o homem em suas respostas às questões que a vida lhe proporciona mediante as situações reais e concretas. Sendo assim, o homem religioso é o homem de audição mais aguda que o irreligioso. O homem religioso é capaz de assumir a sua vida como uma missão a ser cumprida, vivenciando esta missão como uma busca do encontro com esta instância. Segundo Frankl, o homo religiosus foi capaz de completar a dinâmica ontológica. Nele, ser responsável e ser consciente se dão simultaneamente. Por sua vez, o homem irreligioso não foi capaz de questionar para além de sua consciência. A experiência religiosa, portanto, está inserida na senda para uma vida plena de sentido, na qual o homem explora a força de sua dimensão espiritual, permitindo-se ser conduzido por Tu e orientado na dinâmica da própria consciência (Coelho Jr. \& Mahfoud, 2001).

\section{Considerações finais}

$\mathrm{Na}$ medida em que o homem espiritualmente livre não precisa deixar-se absorver por qualquer situação, ele pode, ao mesmo tempo, situar-se sempre "acima" de qualquer situação. E esta capacidade de estar acima das coisas também permite a possibilidade de ele estar acima de si próprio. E tal liberdade é, essencialmente, "liberdade de" algo e "liberdade para" algo.

Segundo Moreira, Abreu e Oliveira (2006), o homem pode realizar suas potencialidades na autotranscendência quando encontra um sentido fora dele mesmo, no encontro autêntico com o outro. A experiência de ser com-o-outro como dimensão da existência possibilita a vivência da conduta moral sempre concreta, situacional -, que por sua vez permite desvelar o sentido dos valores da existência com-ooutro.

A partir da possibilidade de se confrontar o espiritual (logos) do homem com o psicossomático isso significa uma tomada de posição perante as dores e isso representa invariavelmente também se situar "acima" das dores e mazelas. Afinal, quem decide, por último, é a pessoa espiritual, ou seja, a posição pessoal em relação à posição natural. A logoterapia representa, em certo sentido, evidentemente, a "terapêutica causal, isto é, aquela terapêutica que inclui na sua ação apenas a última e verdadeira 'causa"' (Frankl, 1978).

E quando o homem assume uma atitude de aceitação ante dos condicionamentos, no momento em que opta pela responsabilidade, a despeito da irreversibilidade da situação factual, então ele tem a possibilidade de libertar-se para encontrar um sentido real para a sua existência.

Segundo Lukas (1990), a "tríade trágica" integrante básica de nossa existência - é humanamente viável de ser superada pelo enfrentamento com os meios espirituais, a fim de se expandirem nossas vivências e experiências existenciais. Afinal, como o ser humano pode suportar o sofrimento? Por que certas pessoas enfrentam heroicamente as grandes provações 
do destino e outras entram em pânico ou se entregam ante uma aflição mínima?

A capacidade de uma pessoa para superar o sofrimento depende da intensidade de sua realização interna de sentido. Quem basicamente acredita num sentido na sua vida, também é capaz de suportar um grande sofrimento, porque sua vida permeada de sofrimento não perde seu sentido, apesar de ter seu prazer reduzido (Lukas, 1990, p. 173).

Embora haja situações impossíveis ao homem de compreender racionalmente o seu sentido, pela fé e pelo amor é possível aproximar-se dele. Afinal, acima do mundo humano, existe o mundo do suprassentido, o qual dá sentido a todo sofrimento humano. E neste contexto o homo religiosus encontra os recursos fundamentais para a superação de todo e qualquer padecimento. Afinal, "a verdadeira religiosidade não tem caráter de impulso, mas antes de decisão" (Frankl, 1993).

"O ser humano é o ser que decide o que vai se tornar" (Silveira, 2007, p. 104). Parece terrível saber que em cada momento sou responsável pelo próximo; que cada decisão, independentemente se menor ou maior, é uma decisão "para toda a eternidade". E mais, em cada momento eu realizo ou desperdiço uma possibilidade, possibilidade de momento. E cada instante ou momento permite infinitas possibilidades! $\mathrm{E}$ eu posso escolher apenas uma. E as demais eu as condenei e rejeitei a um jamais-ser.

Frankl (1993), ao distinguir a dimensão espiritual da experiência religiosa, elege esta última como uma das expressões da dimensão noética. Ademais, não obstante as limitações deste estudo, conclui-se que a logoterapia, ao resgatar o conceito de homo religiosus, permite a possibilidade da superação da existência humana para além da essência do homo patiens, considerando a resiliência como um fator determinante na identificação e enfrentamento do sofrimento inerente à vida humana e partícipe do seu sentido.

\section{Referências}

Coelho Jr., A. G. \& Mahfoud, M. (2001). As dimensões espiritual e religiosa da experiência humana: distinções e inter-relações na obra de Viktor Frankl. Psicologia USP, 12(2), 95-103.

Frankl, V. E. (1978). Fundamentos antropológicos da psicoterapia. Rio de Janeiro: Zahar.

Frankl, V. E. (1985). Em busca de sentido. Petrópolis: Vozes.

Frankl, V. E. (1988). The will to meaning. Nova Iorque: Meridian Books.
Frankl, V. E. (1990). A questão do sentido em psicoterapia. Campinas: Papirus.

Frankl, V. E. (1991). A psicoterapia na prática. Campinas: Papirus.

Frankl, V. E. (1993). A presença ignorada de deus. Petrópolis: Vozes.

Frankl, V. E. (2003). Psicoterapia e sentido da vida. São Paulo: Quadrante.

Gomes, J. C. V. (1988). A prática da psicoterapia existencial: logoterapia. Petrópolis: Vozes.

Lukas, E. (1989). Logoterapia: a força desafiadora do espirito. São Paulo: Loyola.

Lukas, E. (1990). Mentalização e saúde. Petrópolis: Vozes.

Moreira, J. O., Abreu, A. K. C. \& Oliveira, M. C. (2006). Moralidade e sociabilidade em Frankl: um norte para superação da violência. Psicología em Estudo, 11(3), 627-635.

Pereira, I. S. (2007). A vontade de sentido na obra de Viktor Frankl. Psicologia USP, 18(1), 125-136.

Perez, D. Z. (1997). Perdida de sentido y neurosis existencial. Revista Cubana de Psicología, 14(1), 65-69.

Pettengill, M. A. M. \& Angelo, M. (2000). O sentido do cuidar da criança e da família na comunidade: a experiência da aluna de enfermagem. Revista da Escola de Enfermagem da USP, 34(1), 91-98.

Rodrigues, R. (1991). Fundamentos da logoterapia na clínica psiquiátrica e psicoterápica. Petrópolis: Vozes.

Roehe, M. V. (2005). Revendo idéias de viktor frankl no centenário de seu nascimento. Psico Porto Alegre, 36(3), 311-314.

Silveira, D. R. (2007). O sentido da resiliência: a contribuição de Viktor Emil Frankl. (Dissertação de Mestrado). Universidade Federal de Minas Gerais, Belo Horizonte, Minas Gerais, Brasil.

Silveira, D. R. \& Mahfoud, M. (2008). Contribuições de Viktor Emil Frankl ao conceito de resiliência. Estudos de Psicologia (Campinas), 25(4), 567-576.

Sulzbach, N. (2008). Resgate da dignidade pessoal: uma experiência religiosa. (Monografia de Conclusão do Curso de Especialização em Logoterapia). Curitiba, Paraná, Brasil.

Xausa, I. A. M. (2003). O sentido dos sonhos na psicoterapia em Viktor Frankl. São Paulo: Casa do Psicólogo. 
Recebido em março de 2010

Reformulado em junho de 2010

Aprovado em agosto de 2010

Sobre os autores:

Neir Moreira é mestrando em Teologia pela PUC-PR, pós-graduado em Educação pela FTBP, psicólogo formado pela UFPR, e bacharel em Teologia pela FTBP. Professor adjunto na FATADC.

Adriano Holanda é psicólogo, doutor em Psicologia; professor adjunto da Universidade Federal do Paraná. Editor da Revista da Abordagem Gestáltica, é autor de diversos livros e artigos em Fenomenologia, Religiosidade, GEstaltTerapia e Pesquisa Qualitativa. 